\title{
Expression of a mitochondrial gene orfH79 from CMS-Honglian rice inhibits Escherichia coli growth via deficient oxygen consumption
}

\author{
Xia Ding ${ }^{1}$, Qiusheng Chen ${ }^{1}$, Canming Bao ${ }^{1}$, Aihua Ai ${ }^{1}$, Ying Zhou ${ }^{1}$, Shaobo Li ${ }^{1}$, Hongwei Xie ${ }^{2}$, Youlin Zhu', \\ Yaohui $\mathrm{Cai}^{2}$ and Xiaojue Peng ${ }^{1 *}$
}

\begin{abstract}
Cytoplasmic male sterility (CMS) has often been associated with abnormal mitochondrial open frames (ORF), orfH79 is a mitochondrial chimeric gene responsible for the CMS trait in Honglian $(\mathrm{HL})$ rice. In this study, the weakly produced ORFH79 protein significantly inhibited the growth of E. coli in an oxygen culture, however, the growth of the transformants producing ORFH79 was indistinguishable from the control under anaerobic incubation conditions. In addition, a lower respiration rate, wrinkled bacterial surfaces, and decreased pyruvate kinase and a-ketoglutarate dehydrogenase activities were observed in the ORFH79 produced E. coli. These results indicate that ORFH79 impairs the oxygen respiration of E. coli, which may inhibit E. coli growth.
\end{abstract}

Keywords: Cytoplasmic male sterility, orfH79, E. coli growth, Oxygen respiration

\section{Background}

Cytoplasm male sterility (CMS) is a widespread phenomenon in the plant kingdom. It is maternally inherited and characterized by a failure to produce functional pollen (Gray 1999; Young et al. 1987). In most cases, the failure of pollen development in CMS background is associated with chimeric mitochondrial open reading frames (ORFs) arising from unusual recombination events (Hanson and Bentolila 2004). In previous studies, many CMS-associated genes such as T-maize urf13, sunflower orf522, Brassica Ogura radish orf138 and BT-rice orf79 have been shown to encode peptides that are lethal to $E$. coli (Dewey et al. 1988; Duroc et al. 2005; Nakai et al. 1995; Wang et al. 2006). However, the mechanism by which this occurs remains relatively unknown. In addition, whether

\footnotetext{
*Correspondence: xiaojuepeng@ncu.edu.cn

${ }^{1}$ Key Laboratory of Molecular Biology and Gene Engineering of Jiangxi Province, College of Life Science, Nanchang University, Nanchang 330031, People's Republic of China

Full list of author information is available at the end of the article
}

such a phenomenon is related to the mechanism of CMS has not yet been reported.

Honglian cytoplasmic male sterility (CMS-HL) rice (Oryza sativa) is one of the three typical CMS systems of rice. A mitochondrial chimeric gene named orfH79, located downstream of atp 6 , has been proved to result in the pollen abortion of CMS-HL rice (Peng et al. 2004; Yi et al. 2002). Moreover, transgenic OrfH79 rice showed the accumulation of high levels of ROS, significantly decreased adenylate content, and ATP/ADP ratios, and reduced mitochondrial membrane potential, which mimicked CMS-HL rice (Peng et al. 2004). These physiological features suggest that orfH79 expression impairs mitochondrial function. However, the mechanism by which the aberrant ORFH79 protein affects mitochondrial activity requires further investigation.

Due to the pollen-specific phenotype and because it is not technically feasible to handle plant mitochondria, the CMS mechanism is difficult to study. Usually, the expression pattern of a mitochondrial gene is similar to that of E. coli (Gray 1999). In this paper, we introduced 
the orfH79 gene into E. coli, and we found that the weakly produced ORFH79 protein significantly inhibits the growth of E. coli in an oxygen culture, however, the growth of the transformants producing ORFH79 was indistinguishable from the control under anaerobic incubation conditions. In addition, a lower respiration rate, wrinkled bacterial surfaces, and decreased pyruvate kinase and $\alpha$-ketoglutarate dehydrogenase activities were observed in the ORFH79 produced E. coli. These results indicate that ORFH79 impairs the oxygen respiration of E. coli, which may inhibit E. coli growth.

\section{Methods}

\section{Strains and media}

The strains used in this study, E. coli DH5 $\alpha$ and BL21 (DE3) were stored in Key Laboratory of Molecular and Gene Engineering in Nanchang City. The strain was routinely grown in LB medium (5 g yeast extracts/l, $10 \mathrm{~g}$ peptone $/ \mathrm{l}$, and $10 \mathrm{~g} \mathrm{NaCl} / \mathrm{l}$ ) at $37^{\circ} \mathrm{C}$ with oxygen incubation. For anaerobic incubation, LB medium was prepared per $600-\mathrm{ml}$ anaerobic bottle and sterilized under a strictly anaerobic $\mathrm{H}_{2}$ and $\mathrm{CO}_{2}$ atmosphere (80:20).

\section{Plasmid construction}

The DNA fragment encoding orfH79 was amplified from the CMS-HL rice by PCR using a primer set (forward, $5^{\prime}$ GCCGGATCCATGACAAATCTG CTCCGATGGCTC-3'; reverse, $5^{\prime}$ GCCCTCGAGTTACTTAGGAAAGACTACA CG-3'). The orfH79 gene was ligated to the $p E T-28 a$ vector (Invitrogen) digested with NcoI and XholI to construct the plasmid $p E T$-28a-orfH79. The BL21 (DE3) strains were transformed with plasmids $p E T-28 a-o r f H 79$ and $p E T-28 a$ empty vector. As a control in some experiments, we also used $p E T-28 a$ vector expressed a disulfide isomerase-like protein (PDI) gene, MTH1745, which contained a hygrophobic transmembrane structure from 10 to 30 amino acids in this protein (Ding et al. 2008).

\section{Preparation of cell fraction}

Crude membrane versus cytoplasmic cell fraction were prepared described as Arockiasamy and Krishnaswamy (2000) with some modifications. $100 \mathrm{ml}$ of bacterial cell culture were harvested and centrifuged at $10,000 \times g$ for $5 \mathrm{~min}$ at $4{ }^{\circ} \mathrm{C}$. The precipitation was washed twice with phosphate buffered saline (PBS), and resuspended in the same buffer containing 0.1 M PMSF and 0.1 M PI (both Roche Diagnostics). The suspension was ultrasonicated on ice for $15 \mathrm{~min}$ ( $5 \mathrm{~s}$ on with $5 \mathrm{~s}$ intervals). Cell debris and insoluble proteins were recovered by centrifugation for $1 \mathrm{~h}$ at $10,000 \times g$, and the supernatant was centrifuged at $30,000 \times g$ for $2 \mathrm{~h}$ at $4{ }^{\circ} \mathrm{C}$. The supernatant was retained for further analysis and the pellet containing the crude membrane was resuspended in $200 \mu$ l dilution buffer
(66 mM Tris-Cl, pH 6.8, 2 \% v/v 2-mercaptoethanol, $2 \%$ SDS).

\section{Antibodies and western blot analysis}

Equal amounts of protein from the membrane and cytoplasm were separated by $18 \%$ SDS-PAGE gel at $4{ }^{\circ} \mathrm{C}$, and then transferred onto an Immobilon-PSQ transfer membrane (PVDF type; Millipore) at $80 \mathrm{~V}$ for $40 \mathrm{~min}$. The membrane was incubated in $5 \% \mathrm{w} / \mathrm{v}$ non-fat milk, $0.05 \%$ $\mathrm{v} / \mathrm{v}$ Tween-20, in PBS for $1 \mathrm{~h}$, washed for $10 \mathrm{~min}$ three times in PBST (PBS, $0.05 \% \mathrm{v} / \mathrm{v}$ Tween-20), and incubated in a 1:5000 dilution of mouse antiserum anti-ORFH79 overnight at $4{ }^{\circ} \mathrm{C}$. After four washes with PBST, the membrane was incubated with rabbit anti-mouse IgG conjugated with alkaline phosphatase (AP) in PBST solution for $2 \mathrm{~h}$. After four 10-min washes in PBST, the signal was visualized by chemiluminescent detection (Pierce, Rockford Rockford, IL) according to the manufacturer's protocol. Antibody against ORFH79 was a gift from professor Shaoqing Li, College of Life Science, Wuhan University.

\section{Escherichia coli growth curve assay}

The growth curve assay was performed to ascertain the effect of expressing OrfH79 in E. coli cells were transformed with either $p E T-28 a-o r f H 79$ or $p E T-28 a$. The transformants were incubated in LB medium at $37{ }^{\circ} \mathrm{C}$ overnight. For oxygen incubation, $30 \mathrm{ml} \mathrm{LB}$ medium supplemented with $30 \mu \mathrm{l}$ preculture was incubated at $37^{\circ} \mathrm{C}$, with shaking. At an $\mathrm{OD}_{600}$ of 0.6 , the culture was separated into two equal subcultures. IPTG was added to one of the cultures, at a final concentration of $1 \mathrm{mM}$. The cultures were grown at $37{ }^{\circ} \mathrm{C}$ with shaking $(250 \mathrm{rpm})$, and the cell density $\left(\mathrm{OD}_{600}\right)$ of these culture were monitored by withdrawing aliquots at various times. For anaerobic incubation, $600 \mu \mathrm{l}$ overnight preculture was added to LB medium prepared per $600-\mathrm{ml}$ anaerobic bottle and autoclave under a strictly anaerobic $\mathrm{H}_{2}$ and $\mathrm{CO}_{2}$ atmosphere (80:20), and incubated at $37{ }^{\circ} \mathrm{C}$, with shaking. At an $\mathrm{OD}_{600}$ of 0.3 , the culture was separated into two equal subcultures. IPTG was added to one culture, at a final concentration of $1 \mathrm{mM}$. The cultures were grown at $37^{\circ} \mathrm{C}$ with shaking $(250 \mathrm{rpm})$, and the cell density $\left(\mathrm{OD}_{600}\right)$ of these culture were monitored by withdrawing aliquots at various times.

\section{Respiration measurement}

BL21(DE3) pLYsS cells containing pET-28a-orfH79 and $p E T$-28a were cultured in $5 \mathrm{ml} \mathrm{LB}$ medium supplemented with antibiotics at $37{ }^{\circ} \mathrm{C}$. Each preculture was diluted 1:1000 in fresh LB medium containing antibiotics. The resulting culture was incubated at $37{ }^{\circ} \mathrm{C}$ until the cells reached the early exponential growth phase. Each culture was then divided into two subcultures. One subculture 
was induced with $1 \mathrm{mM}$ IPTG whereas the other was used as a control. Both subcultures were incubated at $37^{\circ} \mathrm{C}$, with shaking, for an additional $2 \mathrm{~h}$. Cellular respiration was measured at HPES-KPR buffer (50 mM HPES, $\mathrm{pH7.4}, 100 \mathrm{mM} \mathrm{NaCL}, 5 \mathrm{mM} \mathrm{KCL}, 1 \mathrm{mM} \mathrm{MgCL} \mathrm{L}_{2}, 1 \mathrm{mM}$ $\mathrm{NaH}_{2} \mathrm{PO}_{4}, 1 \mathrm{mM}$ D-glucose and $1 \mathrm{mM} \mathrm{CaCl}{ }_{2}$ ). Respiration was measured using the temperature-controlled chamber of a chlorolab 2 electrode (Hansatech, UK) containing $2 \mathrm{ml}$ of buffer. The respiration rate was measured by the detection of oxygen consumption at $37^{\circ} \mathrm{C}$.

\section{Membrane observation of $E$. coli by scanning electron microscopeye}

The bacterial cells were fixed with $2.5 \%$ glutaradehyde overnight at $4{ }^{\circ} \mathrm{C}$. The fixed cells were washed three times with phosphate buffer $(0.1 \mathrm{M}, \mathrm{pH} 7.0), 15$ min each time. The bacterial cells were dehydrated in ascending concentration of ethanol $(10,20,30,40,50,60,70,80,90,95$, 100 and $100 \%)$ at 15 min exposure for each concentration. The bacterial cells were further dehydrated in different ratios of ethanol: acetone $(3: 1,1 ; 1$ and 1:3) for $20 \mathrm{~min}$ for each mixture and then washed with pure acetone four times each for $20 \mathrm{~min}$. These bacterial cells were subjected to critical point drying using liquid $\mathrm{CO}_{2}$ and the cells mounted on a stub. These cells were coated with gold and examined by using scanning electron microscope.

\section{Detection of pyruvate kinase and a-ketoglutarate dehydrogenase activity}

BL21(DE3) pLYsS cells, harboring the expression vectors $p E T-28 a-o r f H 79$ and $p E T-28 a$, were cultured in LB medium until the optical density reached $0.6-0.8$. Each culture was then divided into two subcultures. One subculture was induced with $1 \mathrm{mM}$ IPTG whereas the other was used as a control. Cells were harvested at $6 \mathrm{~h}$ and $12 \mathrm{~h}$, after induction with IPTG. Cells were disrupted by sonication and centrifuged to remove cell debris. The supernatants were used to determine the protein quantity and for use in enzymatic assays. Pyruvate kinase activity was measured using the ultraviolet chromatometry method following the protocol of the pyruvate kinase activity assay kit (Nanjing Jiancheng, China). The $\alpha$-ketoglutarate dehydrogenase activity determination was performed described by Flora (Pettit et al. 1973).

\section{Statistical analysis}

All experimental data are the mean of at least three independent replicates, and comparisions between transformants were performed using one way ANOVA with Duncan's multiple range test. All the statistical analyses were performed using SPSS software.

\section{Results}

\section{ORFH79 protein is primarily localized in the membrane} of $E$. coli

We extracted the total protein from E. coli transformants after induction, and then preformed SDS-PAGE and western blot analysis. The ORFH79 protein was not observed on Coomassie-blue gels (data not shown), whereas the production of ORFH79 was confirmed by western blot assay (Fig. 1a). A band of approximately 9KD was detected in the total protein samples from $p E T-28 a-$ orfH79 transformed $E$. coli, and no signal was detected in $E$. coli transformed with the empty plasmid ( $p E T-28 a)$. In addition, the subcellular distribution of ORFH79 was also determined. As shown in Fig. 1b, ORFH79 is primarily distributed in the crude membrane protein fractions (Fig. 1b). These results indicate that the ORFH79 protein is mainly attached to the E. coli membrane.

\section{Expression of orfH79 inhibits the growth of $E$. coli in oxygen culture and has no negative effects on the growth of $E$. coli under anaerobic conditions}

During the induction of orfH79 expression in oxygen culture, we found that the growth rate of the induced pET-28a-orfH79 transformants was significantly inhibited compared to the control, and we then test the cell growth. As shown in Fig. 2a, transformants of $p E T-28 a-$ orfH79 and $p E T-28 a$ exhibited similar growth rates in liquid medium without IPTG, whereas in the IPTG induced culture, ORFH79 production significantly decreased the growth rate of $E$. coli compared with the empty plasmid

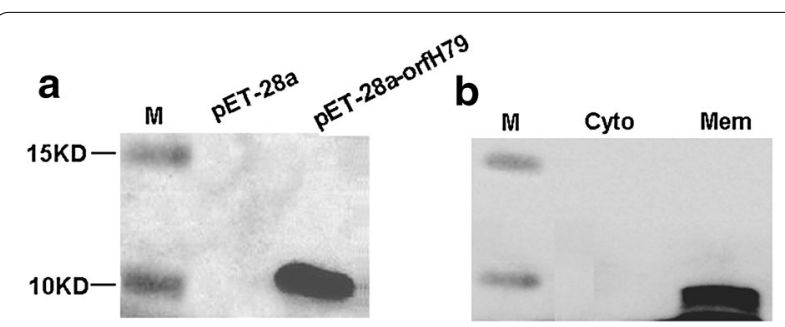

Fig. 1 Western blot analysis of ORFH79 in whole E. coli extracts and fractions. a Detection of ORFH79 in whole E. coli extracts. Total protein was extracts from $p E T$-28a or $p E T$-28a-orfH79 transformants induced with $1 \mathrm{mM} \mathrm{IPTG}$, and subjected to PAGE in a $15 \%$ acylamide gel. Western blot was preformed to detect the production of ORFH79 protein. Signal were obtained in the protein fraction from $p E T-28 a-$ orfH79 transformants. No signal appeared in the protein fraction from $p E T-28 a$ transformants. b Intracellular localization of ORFH79 in E. coli. Crude membrane versus cytoplasmic cell fraction were prepared from pET-28a-orfH79 transformants by series of centrifugation and subjected to PAGE in a $15 \%$ acylamide gel. Western blot was preformed to detect Intracellular localization of ORFH79 in E. coli. Signal were obtained in the crude membrane fraction. $M$ marker; Cyto Cytoplasmic fraction of pET-28a-orfH79 transformants; Mem Crude membrane fraction of pET-28a-orfH79 transformants 
transformants. Additionally, no obvious exponential phase appeared in the growth curve of $p E T-28 a$-orfH 79 transformants in an oxygen culture. In this study, we found that the transformants producing ORFH79 protein have slow growth similar to fermentation growth, therefore, we monitored the anaerobic growth rate of these transformants. As shown in Fig. 2b, under anaerobic incubation conditions, growth curve of the induced $p E T$ 28a-orfH79 transformants was similar to the control. These findings suggest that ORFH79 mediates inhibition of $E$. coli growth and is associated with the inhibition of oxidative phosphorylation.

\section{The respiration rate is reduced in orfH79 expressing transformants}

Because ORFH79 is localized in the membrane of E. coli, and because orfH79 expression inhibits $E$. coli growth in an oxygen culture, whereas it has no negative effects on the growth of $E$. coli under anaerobic incubation conditions, we focused on the respiration rate of the transformants. We used an oxygen electrode to measure the oxygen consumption of bacteria that did and did not produce ORFH79. Oxygen consumption was measured at induction and $2 \mathrm{~h}$ later. As shown Fig. 2c, the respiration rates of the orfH79 expressing transformants were significantly decreased by about $65.2 \%$ compared with the control, suggesting that oxygen consumption was affected by ORFH79 in E. coli cells.

\section{Wrinkled bacterial surfaces appear in ORFH79 producing E. coli}

Oxygen consumption in $E$. coli cells occur via respiration chain, which is distributed in the bacterial plasma membrane. Although ORFH79 appear to weaken oxidative respiration, we want to know whether the membrane structure of the bacterial is normal, then the SEM was used to

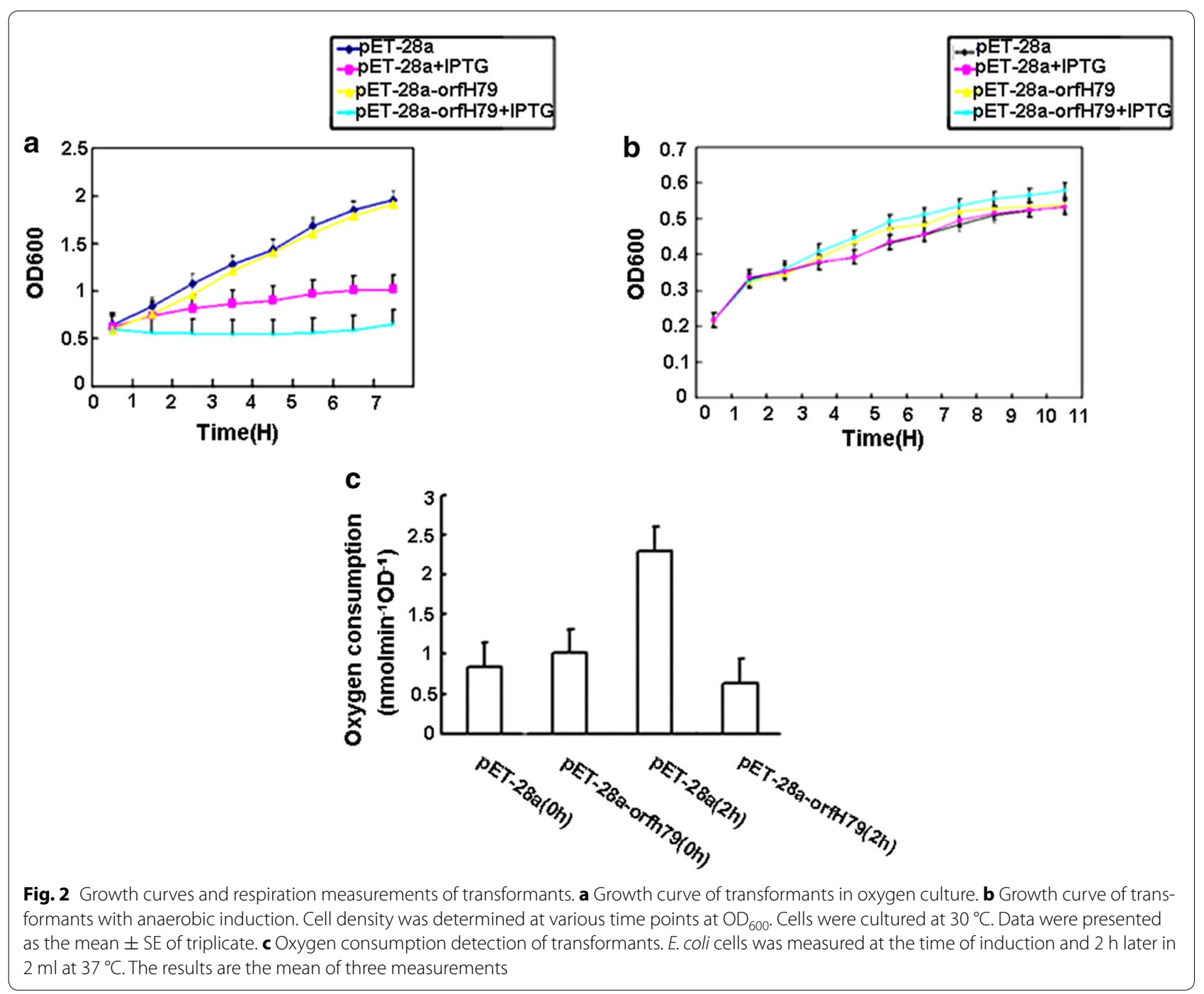



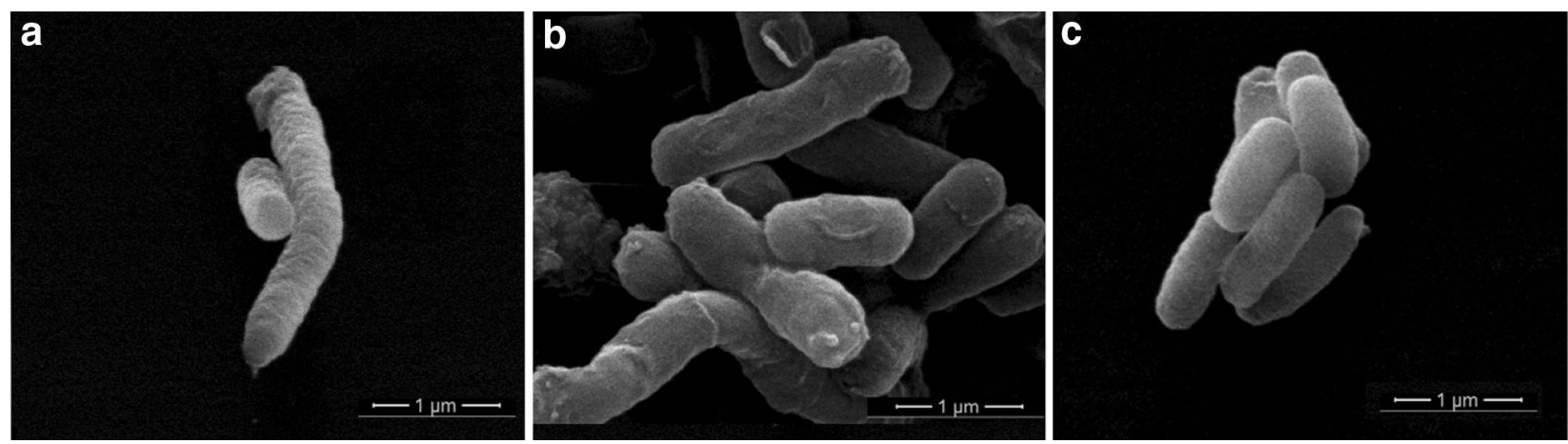

Fig. 3 Scanning electron microscope images of transformants. a Images of ORFH79 protein produced E. coli cells. b Images of empty plasmid transformed E. coli cells. Bar 1 um. c Images of MTH1745 protein produced E. coli cells

evaluate the ultrastructural changes of the cell membranes from bacteria that did and did not produce ORFH79. As shown in Fig. 3, the control cells had well-defined and smooth membranes, whereas ORFH79 production resulted in a wrinkled membrane surface. The winkled membrane is consistent with the dysfunction of respiration in ORFH79 producing $E$. coli cells, proving direct evidence that ORFH79 impairs the oxygen respiration of E. coli.

\section{ORFH79 production decreased pyruvate kinase and a-ketoglutarate dehydrogenase activity}

Oxidative phosphorylation involves a series of respiratory related enzymes. Pyruvate kinase and $\alpha$-ketoglutarate dehydrogenase are two of important enzymes preserve the efficiency of oxygen respiration in the cell. Therefore, we monitored the activity of pyruvate kinase and $\alpha$-ketoglutarate dehydrogenase in these transformants at 6 and $12 \mathrm{~h}$ of induction, respectively. The data show that the pyruvate kinase activity of ORFH79 producing transformants was significantly lower than the empty plasmid transformants at both $6 \mathrm{~h}$ and $12 \mathrm{~h}$ of induction later, and was twofold and ninefold lower than that of control respectively. The $\alpha$-ketoglutarate dehydrogenase activity in ORFH79 producing transformants was significantly decreased by $52.8-54.4 \%$ compared with the control after 6 and $12 \mathrm{~h}$ of induction. These results indicate that the production of ORFH79 caused decrease respiration related enzyme activity in E. coli (Fig. 4).

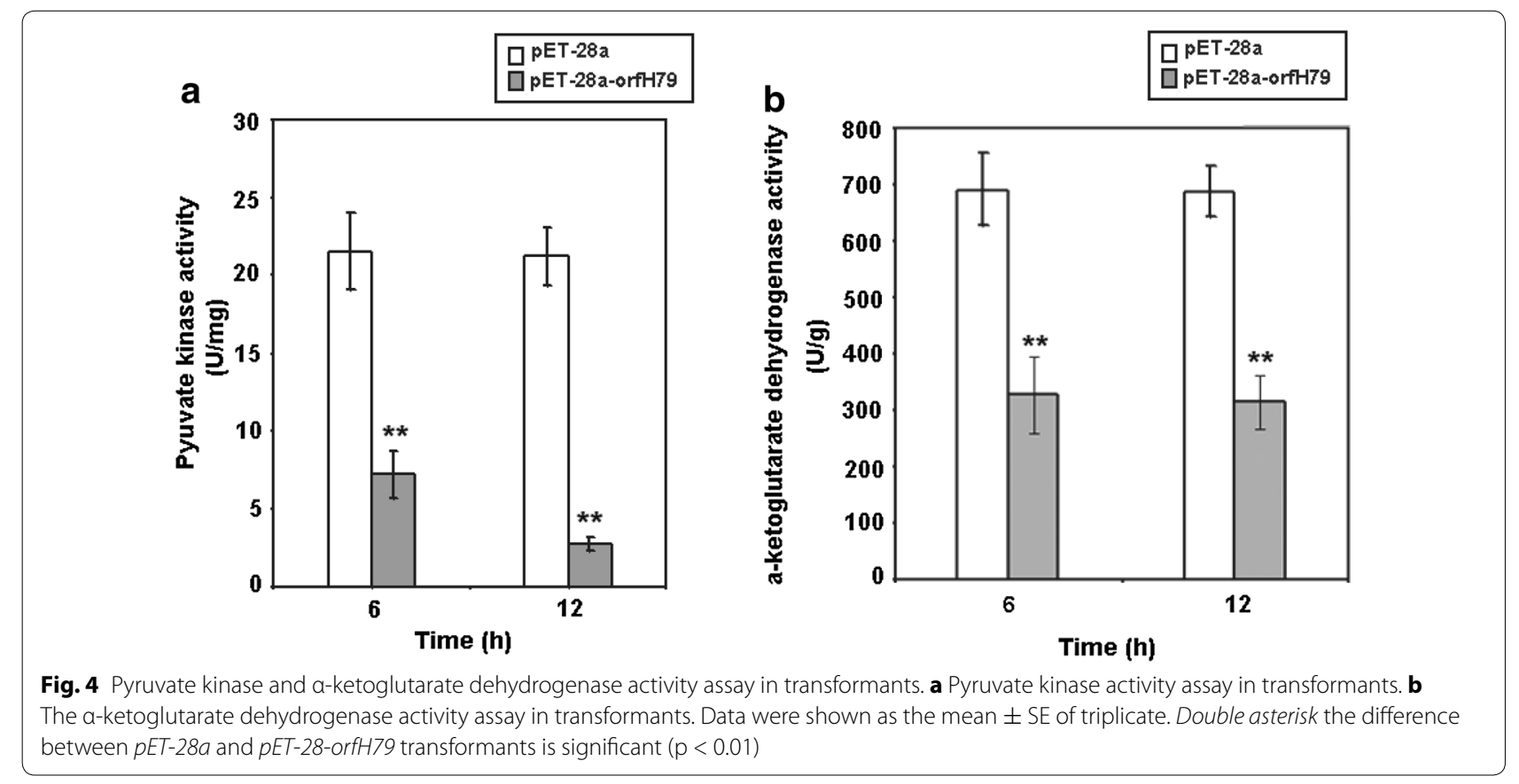




\section{Discussion}

Recent reports about mechanism of CMS have provided insight into the mitochondrial respiratory chain complex. Luo et al. (2013) reported that WA352, a mitochondrial protein responsible for CMS of wild abortive rice, interacts with mitochondrial protein COX11. Furthermore, the ORFH79 protein, was founded to bind to mitochondrial complex III and decrease its enzyme interaction with P61 (Wang et al. 2013). These recent findings focus the attention regarding the mechanism of CMS mechanism on the interaction between CMS associated proteins and mitochondrial respiratory complex. However, it is not technically feasible to handle the pollen-specific phenotype, and the bioinformatics techniques for plant mitochondria must be improved to overcome the difficulties in studying plant pollen mitochondrial respiratory chain.

The respiratory complex is conserved between the E. coli membrane and mitochondria (Esterhazy et al. 2008; Grigorieff 1998; Guenebaut et al. 1998). In addition, the gene transcription and translation patterns in mitochondria are similar to E. coli (Gray 1999). Many reports indicate that the dysfunction of mitochondria in CMS plants is associated with the deficiency in oxidative phosphorylation, while direct evidence for this is lacking. Our experiments showed that the weakly produced ORFH79 protein significantly inhibits the growth of $E$. coli in oxygen culture, and was accompanied by a lower respiration rate, decreased pyruvate kinase and $\alpha$-ketoglutarate dehydrogenase activity in E. coli, and wrinkled bacterial surfaces. Moreover, the growth of the ORFH79 producing transformants under anaerobic incubation conditions was not changed, providing direct evidence that ORFH79 impairs oxygen respiration. Additionally, it is notable that a typical exponential phase did not occur in the growth curve of ORFH79 producing $E$. coli in oxygen culture. Considering the deficient oxygen consumption with the increases demand for energy equivalents for rapid organism growth and division at the exponential stage, we infer that the expression of orfH79 in $E$. coli impair the oxygen respiration such that the particularly high level energy demands for the E. coli cell growth and divided at the exponential stage can-not be met. Taken together, our find in the experiment provide more detailed information about the mechanism on CMS in Honglian rice using the E. coli model system.

\section{Conclusion}

In summary, we found the weakly produced ORFH79 protein significantly inhibits the growth of E. coli in oxygen culture, and was accompanied by a lower respiration rate, decreased pyruvate kinase and $\alpha$-ketoglutarate dehydrogenase activity in E. coli, and wrinkled bacterial surfaces. Moreover, the growth of the ORFH79 producing transformants under anaerobic incubation conditions was not changed. These results indicate that orfH79 protein impairs oxygen respiration, which may inhibit E. coli growth.

\section{Authors' contributions}

XJP designed the study and wrote the manuscript. XD performed most of the experiment. QSC and CMB helped in carrying out plasmid construction and western blot. HAA helped in testing the cell growth. YZ and SBL helped in detection enzymes activity. HWX helped in observing the E. coli using scanning electron microscopy, YLZ and YHC helped in analyzing the data. All authors read and approved the final manuscript.

\section{Author details \\ ${ }^{1}$ Key Laboratory of Molecular Biology and Gene Engineering of Jiangxi Prov- ince, College of Life Science, Nanchang University, Nanchang 330031, People's Republic of China. ${ }^{2}$ Jiangxi Super-Rice Research and Development Center, Nanchang 330200, People's Republic of China.}

\section{Acknowledgements}

This work was supported by Natural Science Foundation of China (31160270, 31401038, 31160019, 31360332), Project of Jiangxi Provincial Department of Education (No. GJJ13102), and Jiangxi province significant project of scientific and technology (No. 20143ACF60008).

\section{Competing interests}

The authors declare that they have no competing interests.

Received: 23 December 2015 Accepted: 12 July 2016

Published online: 19 July 2016

\section{References}

Arockiasamy A, Krishnaswamy S (2000) Purification of integral outermembrane protein $\mathrm{OmpC}$, a surface antigen from Salmonella typhi for structure-function studies: a method applicable to entero-bacterial major outer-membrane protein. Anal Biochem 283:64-70

Dewey RE, Siedow JN, Timothy DH, Levings CS 3rd (1988) A 13-kilodalton maize mitochondrial protein in E. coli confers sensitivity to Bipolaris maydis toxin. Science 239:293-295

Ding X, Lv ZM, Zhao Y, Min H, Yang WJ (2008) MTH1745, a protein disulfide isomerase-like protein from thermophilic archaea, Methanothermobacter thermoautotrophicum involving in stress response. Cell Stress Chaperones 13:239-246

Duroc Y, Gaillard C, Hiard S, Defrance MC, Pelletier G, Budar F (2005) Biochemical and functional characterization of ORF138, a mitochondrial protein responsible for Ogura cytoplasmic male sterility in Brassiceae. Biochimie 87:1089-1100

Esterhazy D, King MS, Yakovlev G, Hirst J (2008) Production of reactive oxygen species by complex I (NADH: ubiquinone oxidoreductase) from Escherichia coli and comparison to the enzyme from mitochondria. Biochemistry 47:3964-3971

Gray MW (1999) Evolution of organellar genomes. Curr Opin Genet Dev 9:678-687

Grigorieff N (1998) Three-dimensional structure of bovine NADH: ubiquinone oxidoreductase (complex I) at $22 \mathrm{~A}$ in ice. J Mol Biol 277:1033-1046

Guenebaut V, Schlitt A, Weiss H, Leonard K, Friedrich T (1998) Consistent structure between bacterial and mitochondrial NADH: ubiquinone oxidoreductase (complex I). J Mol Biol 276:105-112

Hanson MR, Bentolila S (2004) Interactions of mitochondrial and nuclear genes that affect male gametophyte development. Plant Cell 16(Suppl):S154-S169

Luo D, Xu H, Liu Z, Guo J, Li H, Chen L, Fang C, Zhang Q, Bai M, Yao N, Wu H, Ji C, Zheng H, Chen Y, Ye S, Li X, Zhao X, Li R, Liu YG (2013) A detrimental mitochondrial-nuclear interaction causes cytoplasmic male sterility in rice. Nat Genet 45:573-577 
Nakai S, Noda ND, Kondo M, Terachi T (1995) High-level expression of a mitochondrial orf522 gene from the male-sterile sunflower is lethal to E. coli. Breed Sci 45:233-236

Peng X, Wang K, Hu C, Zhu Y, Wang T, Yang J, Tong J, Li S (2004) The mitochondrial gene orfH79 plays a critical role in impairing both male gametophyte development and root growth in CMS-Honglian rice. BMC Plant Biol 10:125

Pettit FH, Hamilton L, Munk P, Namihira G, Eley MH, Willms CR, Reed LJ (1973) Alpha-keto acid dehydrogenase complexes. XIX. Subunit structure of the Escherichia coli alpha-ketoglutarate dehydrogenase complex. J Biol Chem 248:5282-5290

Wang Z, Zou Y, Li X, Zhang Q, Chen L, Wu H, Su D, Chen Y, Guo J, Luo D, Long Y, Zhong Y, Liu YG (2006) Cytoplasmic male sterility of rice with boro
Il cytoplasm is caused by a cytotoxic peptide and is restored by two related PPR motif genes via distinct modes of mRNA silencing. Plant cell 18:676-687

Wang K, Gao F, Ji Y, Liu Y, Dan Z, Yang P, Zhu Y, Li S (2013) ORFH79 impairs mitochondrial function via interaction with a subunit of electron transport chain complex III in Honglian cytoplasmic male sterile rice. New Phytol 198:408-418

Yi P, Wang L, Sun Q, Zhu Y (2002) Discovery of mitochondrial Chimeric gene associated with male sterility of HL-rice. Chin Sci Bull 47:744-747

Young JD, Cohn ZA, Gilula NB (1987) Functional assembly of gap junction conductance in lipid bilayers: demonstration that the major $27 \mathrm{kd}$ protein forms the junctional channel. Cell 48:733-743

\section{Submit your manuscript to a SpringerOpen ${ }^{\circ}$ journal and benefit from:}

- Convenient online submission

- Rigorous peer review

- Immediate publication on acceptance

- Open access: articles freely available online

- High visibility within the field

- Retaining the copyright to your article 